\title{
Prevalence of Diabetic Retinopathy and its Associated Factors among Diabetic Patients in Primary Care Clinics, Kuantan, Pahang
}

\author{
Mohd Aznan $M A^{\mathrm{a}, \mathrm{b}}$, Khairidzan $M K^{\mathrm{c}}$, Razman $\mathrm{MR}^{\mathrm{d}}$, Fa'iza $\mathrm{A}^{\mathrm{a}, \mathrm{b}}$ \\ ${ }^{a}$ Department of Family Medicine, Kulliyyah of Medicine, International Islamic University Malaysia, Kuantan, \\ Pahang \\ ${ }^{b}$ Non-Communicable Diseases Research Unit, Kulliyyah of Medicine, International Islamic University \\ Malaysia, Kuantan, Pahang \\ 'Department of Ophthalmology, Kulliyyah of Medicine, International Islamic University Malaysia, Kuantan, \\ Pahang \\ dDepartment of Community Medicine, Kulliyyah of Medicine, International Islamic University Malaysia, \\ Kuantan, Pahang
}

\section{ABSTRACT}

Introduction: Diabetic retinopathy (DR) is one of the commonest complications of diabetes mellitus. This study was to determine the prevalence of DR and its association with chronic kidney disease (CKD), high $\mathrm{HbA1C}$ and dyslipidemia among diabetic patients in government primary care clinics. Materials and Methods: A cross sectional study was carried out. The respondents were selected from diabetic registry at two government primary care clinics in Kuantan, Pahang via stratified random sampling method during the study period from May 2010 to April 2011. The respondents were interviewed and assessed clinically using a structured questionnaire. Retinal examination was performed by accredited staff using non-mydratic retinal imaging and DR was classified according to the International Clinical Diabetic Retinopathy Disease Severity Scale. Results: Out of 400 respondents, $58.8 \%$ were diagnosed with diabetes less than 5 years and $51.0 \%$ had uncontrolled blood pressure $(>130 / 80 \mathrm{mmHg})$. The prevalence of DR and maculopathy were $33.5 \%$ and of $17.8 \%$ respectively. Most of these patients $(22.3 \%)$ had mild non-proliferative DR. DR patients had higher percentages CKD (17.9\% vs. 6.8\%; $\mathrm{p}<0.001)$ and a higher mean of HbA1C (8.69 vs. 8.11; $\mathrm{p}=0.015)$ compared to non-DR patients. The study revealed that DR was independently associated with CKD $\{0 R: 3.46,95 \% \mathrm{Cl}$ $(1.76,6.80)\}$ and high $\mathrm{HbA} 1 \mathrm{c}$ \{OR: 1.12, 95\% CI $(1.02,1.23)\}$. Those with dyslipidemia however, has $39 \%$ less risk of DR \{OR: $0.61,95 \% \mathrm{Cl}(0.39,0.94)\}$. Conclusion: This study showed that diabetic patients with CKD and high $\mathrm{HbA} 1 \mathrm{c}$ have greater risks to develop DR but has protective risk with dyslipidemia.

KEYWORDS: diabetic retinopathy (DR), non-mydratic retinal camera, primary care clinic.

INTRODUCTION

Diabetes mellitus (DM) is an important public health concern. Globally there is a rising trend in the prevalence of DM due to many factors such as aging, urbanization and increasing prevalence of obesity and physical inactivity. The International Diabetes Federation (IDF) predicts that the prevalence of DM

Corresponding Author:

Assoc. Prof Dr Mohd Aznan Md Aris

Department of Family Medicine,

Kulliyyah of Medicine,

International Islamic University Malaysia,

25200 Kuantan, Pahang, Malaysia.

Tel: +6095704571, Fax: +6095716978

Email:aznan@iium.edu.my in South East Asia will increase by two folds by the year $2025 .^{1}$

The World Health Organization (WHO) has estimated that in the year 2030, Malaysia would have a total of 2.48 million people with DM. ${ }^{2}$ In Malaysia, the first National Health and Morbidity Survey I (NHMS I) conducted in 1986 reported a DM prevalence of $6.3 \%$ which had risen to $8.3 \%$ and $14.9 \%$ in the NHMS II (1996) and NHMS III (2006) respectively. ${ }^{3}$ In the latest NHMS IV 2011 report, the overall prevalence of DM was $15.2 \%$ and $20.8 \%$ in those aged above 18 and 30 years respectively. ${ }^{4}$ NHMS I and II involved subjects aged above 30 years while NHMS III and IV were conducted among subjects above 18 years of age. ${ }^{4}$ 
DM is a complex disease with multiple complications namely nephropathy, neuropathy, retinopathy, dermatopathy and cardiovascular disease. ${ }^{13}$ Diabetic retinopathy (DR) is the leading cause of acquired blindness in the United States in patients aged 20 to 74 years. $^{5-7}$ Studies showed that early detection of diabetes, better glucose control, and early detection and treatment of DR can slow the progression of DR and prevent the development of blindness. ${ }^{8,9}$ Vulnerable populations, including minorities and the elderly are disproportionately affected by diabetes. They have less access to medical care and are therefore disproportionately affected by the diabetic complications, including DR. ${ }^{10,11}$ Effective screening and treatment programs can greatly reduce the burden of blindness in these populations. ${ }^{12}$

In Malaysia, diabetic eye disease is the commonest cause of visual loss among adults of working age. Prevalence of DR is closely linked to the duration of DM. At the time of diagnosis, less than $5 \%$ will have retinopathy while the prevalence rises to $40-50 \%$ after 10 years. Almost all patients with type 1 diabetes mellitus (T1DM) and more than 60\% patients with type 2 diabetes mellitus (T2DM) have some degree of retinopathy after 20 years of the disease. $^{2}$

Hence, effort to detect DR at an early stage is crucial. International and national guidelines for screening of this disease have been published, in which an annual fundus examination is mandatory for all diabetic patients. ${ }^{13}$ Effective screening and treatment programmes can greatly reduce the burden of blindness in the vulnerable population. ${ }^{12}$ The aim of this study was to measure the prevalence of DR in Kuantan population and its associated factors by using the Topcon TRC-NW6S Non-Mydriatic Camera as a sole screening instrument, in implementing effective screening and treatment programmes for diabetic patients with DR in primary care setting.

\section{METHODOLOGY}

A cross sectional study was carried out. The study adhered to the tenets of the declaration of Helsinki and was approved by Kulliyyah of Medicine research committee. The respondents were selected through stratified random sampling from the list of patients aged 18 years and older who attended the diabetic clinic in selected government primary care clinics in Kuantan, Pahang during the study period from $1^{\text {st }}$ May 2010 to $30^{\text {rd }}$ April 2011.

The data were collected in two parts. The first part used the questionnaire which consists of the sociodemographic and clinical characteristics of respondents. The clinical characteristics such as body mass index (BMI), waist circumference, blood pressure, systemic co-morbidity such as treated hypertension and dyslipidemia, chronic kidney disease (CKD), visual impairment and HbA1c were collected during the first visit.

The second part was to screen the presence of diabetic retinopathy (DR) by using the non-mydratic retina camera. There were two non-mydratic retina cameras available at government primary care clinics in Kuantan located at Klinik Kesihatan (KK) Jaya Gading and KK Balok. All selected respondents were given appointments at these clinics for retinal photography.

Retinal photography was taken using the Topcon TRC-NW6S Non-mydriatic Retinal Camera. It was performed by accredited technical staff using the nine-field photography. All photos were taken by the technicians in both clinics. The photographic images were then read by a trained primary care physician who is the main author and the final findings were confirmed by the consultant ophthalmologist. The retinal abnormalities were classified according to the International Clinical Diabetic Retinopathy Disease Severity Scale and the International Clinical Diabetic Macular Oedema Disease Severity Scale. ${ }^{14}$

The data was analyzed using the IBM Corp. SPSS Statistics for Windows, Version 19 Armonk, NY: IBM Corp. Descriptive analysis was carried out by calculating the frequencies and percentages for the categorical variables, while continuous variables were summarized as mean and standard deviation (SD). Chi-square analysis was used for categorical variables and for numerical variables; independent sample t-test was used to look for statistical significance of association. Logistic regression analyses were performed to estimate the odds ratios (ORs) and $95 \%$ confidence interval $(\mathrm{Cl})$ as the measure of association between CKD, high HbA1C and dyslipidemia with DR. 
The $95 \% \mathrm{Cl}$ and adjusted OR (aOR) were reported. A $p$ value of $<0.05$ was considered as statistically significant.

Participation in the study was voluntary and each participant could withdraw from the study at any time. The questionnaire was accompanied by a cover letter explaining the purpose of the study and reassuring respondents of the confidentiality of the survey. Ethics approval was obtained from Kulliyyah Ethics Meeting No. 3/2009.

\section{RESULTS}

During the study period, 400 respondents agreed to be enrolled in the study. The mean (SD) age of patients was 51(11.1) years old. Majority were Malays $(92.8 \%)$ and females $(66.7 \%)$ with secondary education background (50.5\%). Most of them were diagnosed to have diabetes mellitus (DM) for less

Table I: Socio-demographic characteristics of diabetic mellitus patients $(n=400)$

\begin{tabular}{llll}
\hline Variable & & No & (\%) \\
\hline Age (years) & & 51 & $(11.1)^{\mathrm{a}}$ \\
Gender & Male & 133 & $(33.3)$ \\
Race & Female & 267 & $(66.7)$ \\
& Malay & 371 & $(92.8)$ \\
& Chinese & 16 & $(4.0)$ \\
& Indian & 10 & $(2.5)$ \\
Education & Others & 3 & $(0.8)$ \\
& No formal & 78 & $(19.5)$ \\
& Primary & 96 & $(24.3)$ \\
Duration DM & Secondary & 202 & $(50.5)$ \\
(years) & Higher & 23 & $(5.8)$ \\
& $<1$ & 74 & $(18.5)$ \\
Smoking & $1-5$ & 161 & $(40.3)$ \\
& $>5$ & 165 & $(41.3)$ \\
& No & 365 & $(91.3)$ \\
\hline
\end{tabular}

${ }^{a}$ mean (SD)

Table II shows the clinical characteristics of respondents in this study. Majority of these diabetic patients have systemic co-morbidities such as hypertension and dyslipidemia. About $10.5 \%$ of them have chronic kidney disease (CKD). Majority still have good vision (81\%) and almost half of them have uncontrolled blood pressure. They also have uncontrolled DM as shown by high mean $\mathrm{HbA1c}$ level (8.3\%).
Table II: Clinical characteristics of diabetic patients $(\mathrm{n}=400)$

\begin{tabular}{|c|c|c|c|}
\hline Variable & & No & (\%) \\
\hline Systemic co-morbidity & No & 68 & $(17.0)$ \\
\hline Hypertension & $\begin{array}{l}\text { Yes } \\
\text { No }\end{array}$ & $\begin{array}{l}332 \\
98\end{array}$ & $\begin{array}{l}(83.0) \\
(24.5)\end{array}$ \\
\hline Dyslipidemia & $\begin{array}{l}\text { Yes } \\
\text { No }\end{array}$ & $\begin{array}{l}302 \\
173\end{array}$ & $\begin{array}{l}(75.5) \\
(43.3)\end{array}$ \\
\hline Chronic kidney & $\begin{array}{l}\text { Yes } \\
\text { No }\end{array}$ & $\begin{array}{l}227 \\
358\end{array}$ & $\begin{array}{l}(55.6) \\
(89.5)\end{array}$ \\
\hline $\begin{array}{l}\text { diseases } \\
\text { Visual Impairment }\end{array}$ & $\begin{array}{l}\text { Yes } \\
\text { Right eye }\end{array}$ & $\begin{array}{l}42 \\
84\end{array}$ & $\begin{array}{l}(10.5) \\
(21.1)\end{array}$ \\
\hline Total Visual & $\begin{array}{l}\text { Left eye } \\
\text { No }\end{array}$ & $\begin{array}{l}109 \\
324\end{array}$ & $\begin{array}{l}(27.3) \\
(81.0)\end{array}$ \\
\hline $\begin{array}{l}\text { Impairment } \\
\text { Blood pressure }\end{array}$ & $\begin{array}{l}\text { Yes } \\
\leq 130 / 80\end{array}$ & $\begin{array}{l}76 \\
204\end{array}$ & $\begin{array}{l}(19.0) \\
(51.0)\end{array}$ \\
\hline $\begin{array}{l}(\mathrm{mmHg}) \\
\operatorname{HBA} 1 \mathrm{C}(\%)\end{array}$ & $>130 / 80$ & $\begin{array}{l}196 \\
8.3\end{array}$ & $\begin{array}{l}(49.0) \\
\left(2.3^{\mathrm{a}}\right)\end{array}$ \\
\hline BMI $\left(\mathrm{kg} / \mathrm{m}^{2}\right)$ & & 27.8 & $\left(5.35^{\mathrm{a}}\right)$ \\
\hline Waist circumference & & 94.5 & $\left(11.53^{\mathrm{a}}\right)$ \\
\hline
\end{tabular}

${ }^{a}$ mean (SD)

This study revealed that 134 diabetic patients had DR with a prevalence of $33.5 \%$. It was also found that $71(17.8 \%)$ of them had both DR and diabetic maculopathy (Figure 1). Majority of these patients (22.3\%) had mild non-proliferative diabetic retinopathy (NPDR) based on the total of number of eyes of diabetic patients (Figure 2). Examples of retinal photography taken in the study are shown in Figures 3 and 4.

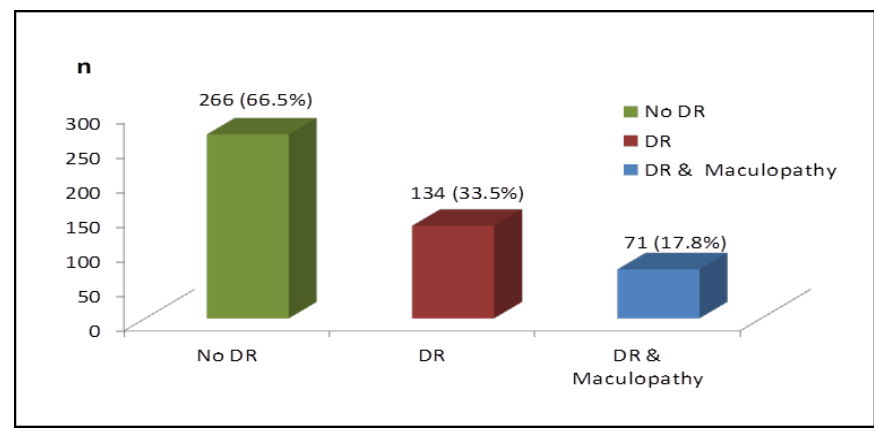

Figure 1: Number and percentages of diabetic retinopathy (DR) status in 400 diabetic patients

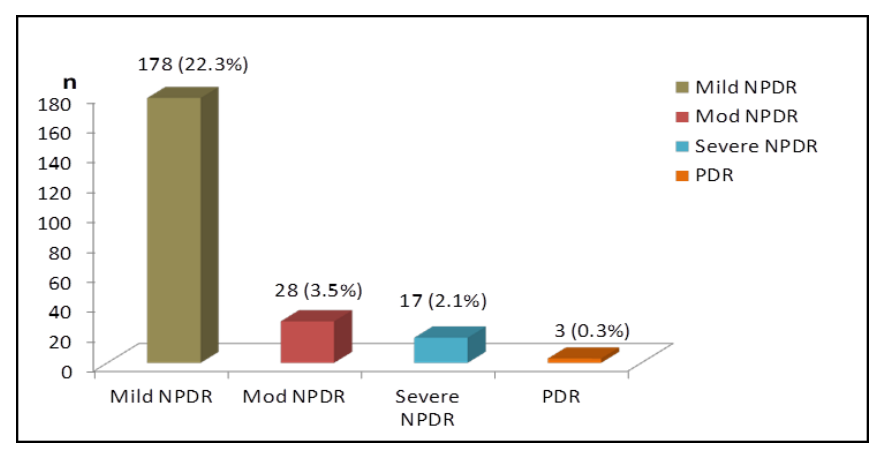

Figure 2: Types of diabetic retinopathy (DR) in the total eyes of respondents $(n=800)$ 


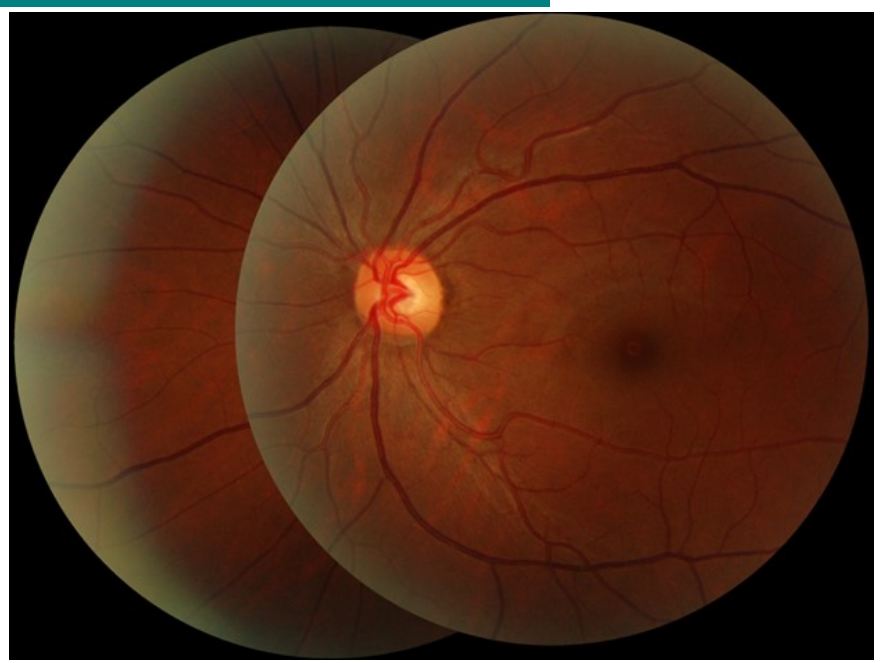

Figure 3: Normal or no diabetic retinopathy of left eye

There were no statistically significant differences in terms of age, gender, education background, duration of DM, history of smoking, presence of systemic co-morbidity and visual impairment between both groups of 'Diabetic Retinopathy' (DR)

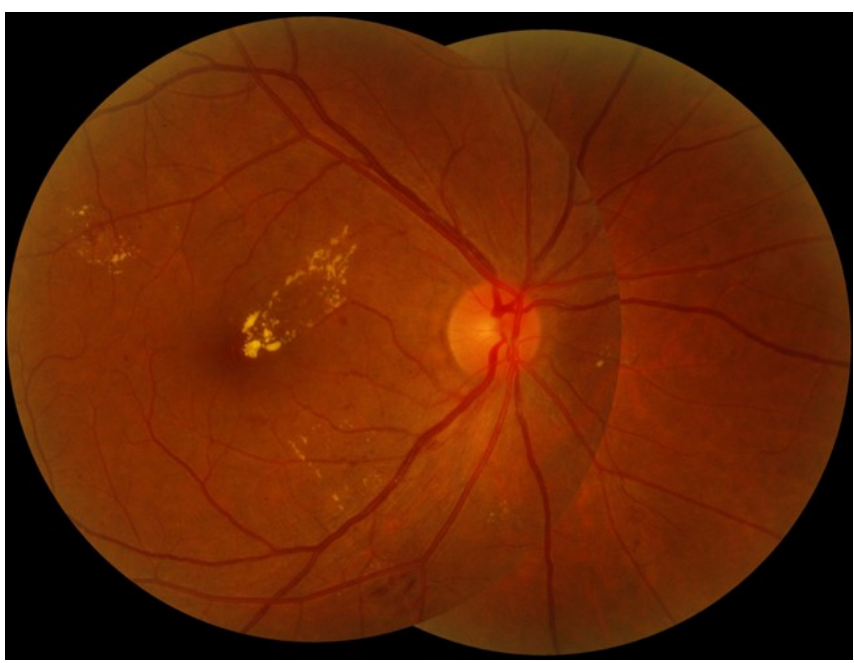

Figure 4: Mild non-proliferative diabetic retinopathy NPDR with maculopathy of right eye

and 'No Diabetic Retinopathy' (NDR). Diabetic patients with DR have higher percentages of CKD (17.9\% vs. $6.8 \% ; p<0.001)$ and a higher mean of HbA1c (8.69 vs. 8.11; $\mathrm{p}=0.015)$ (Table III).

Table III: The clinical characteristics of Diabetic Patients by Status of DR

\begin{tabular}{|c|c|c|c|c|}
\hline & & $\begin{array}{c}\text { Patients without } \\
\text { diabetic retinopathy } \\
\text { (n }=266) \\
\text { No. }(\%)\end{array}$ & $\begin{array}{c}\text { Patients with } \\
\text { diabetic retinopathy } \\
(n=134) \\
\text { No. }(\%)\end{array}$ & value $^{\text {a }}$ \\
\hline \multirow[t]{2}{*}{ Systemic co-morbidity } & No & $42(15.8)$ & $26(19.4)$ & \multirow{2}{*}{0.364} \\
\hline & Yes & $224(84.2)$ & $108(80.6)$ & \\
\hline \multirow[t]{2}{*}{ Hypertension } & No & $60(22.6)$ & $38(28.4)$ & \multirow{2}{*}{0.203} \\
\hline & Yes & $206(77.4)$ & $96(71.6)$ & \\
\hline \multirow[t]{2}{*}{ Dyslipidemia } & No & $108(40.8)$ & $65(48.5)$ & \multirow{2}{*}{0.132} \\
\hline & Yes & $158(59.2)$ & $69(51.5)$ & \\
\hline \multirow[t]{2}{*}{ Chronic kidney didease } & No & $248(93.2)$ & $110(82.1)$ & \multirow{2}{*}{$<0.001$} \\
\hline & Yes & $18(6.8)$ & $24(17.9)$ & \\
\hline \multirow[t]{2}{*}{ Visual impairment } & Right eye & $58(21.8)$ & $26(19.4)$ & 0.578 \\
\hline & Left eye & $74(27.8)$ & $35(26.1)$ & 0.719 \\
\hline \multirow[t]{2}{*}{ Total visual impairment } & No & $212(79.7)$ & $112(83.6)$ & \multirow{2}{*}{0.350} \\
\hline & Yes & $54(20.3)$ & $22(16.4)$ & \\
\hline \multirow[t]{2}{*}{ Blood pressure $(\mathrm{mm} / \mathrm{Hg})$} & $\leq 130 / 80$ & $144(54.0)$ & $60(44.8)$ & \multirow{2}{*}{0.077} \\
\hline & $>130 / 80$ & $122(46.0)$ & $74(55.2)$ & \\
\hline HbA1c (\%) & & $8.11(2.34)^{b}$ & $8.69(2.16)^{\mathrm{b}}$ & 0.015 \\
\hline $\operatorname{BMI}\left(\mathrm{kg} / \mathrm{m}^{2}\right)$ & & $28.1(5.74)^{b}$ & $27.5(4.47)^{\mathrm{b}}$ & 0.202 \\
\hline Waist circumference & & $94.3(11.76)^{\mathrm{b}}$ & $94.7(11.13)^{\mathrm{b}}$ & 0.769 \\
\hline
\end{tabular}

Unless otherwise specified, number and \% values are given, ${ }^{a}$ comparing between status of $D R,{ }^{b}$ mean (SD). 
The study also revealed that DR was independently associated with CKD \{OR: 3.46, 95\% Cl $(1.76,6.80)\}$, high HbA1C \{OR: $1.12,95 \% \mathrm{Cl}(1.02,1.23)\}$ and dyslipidemia \{OR: $0.61,95 \% \mathrm{Cl}(0.39,0.94)\}$ (Table IV).

Table IV: Multivariate Analysis* of factors associated with diabetic retinopathy $(n=134)$

\begin{tabular}{llll}
\hline & aOR & $95 \% \mathrm{Cl}$ & $p$ value \\
\hline Dyslipidemia & 0.61 & $0.39,0.94$ & 0.028 \\
HbA1c & 1.12 & $1.02,1.23$ & 0.014 \\
$\begin{array}{l}\text { Chronic kidney } \\
\text { disease }\end{array}$ & 3.46 & $1.76,6.80$ & $<0.001$ \\
\hline
\end{tabular}

*Logistic regression

\section{DISCUSSION and CONCLUSION}

The overall prevalence of diabetic retinopathy (DR) and maculopathy in this study were $33.5 \%$ and $17.8 \%$ respectively. This result is lower than the nationa $\mathrm{l}^{15}$ and Singapore Malay eye ${ }^{16}$ studies which showed the prevalence of DR as $36.8 \%$ and $35 \%$ respectively, but with higher in the prevalence of maculopathy (9.5\% and $5.7 \%$ respectively). Another study at a primary care clinic in Muar showed a higher prevalence of DR and maculopathy (47.4\% and $59.2 \%$ respectively). ${ }^{17}$ Most of these patients had mild non-proliferative diabetic retinopathy (NPDR), which is similar to previous studies. ${ }^{15-17}$

In this study, the mean of DM duration with DR was 5.9 years. This result is similar to previous study conducted at Muar ${ }^{17}$ but lower than National Eye Database 2007 study ${ }^{15}$ which had a mean of DM with DR of 9.9 years. It's well known that the longer a patient being diagnosed with DM, the greater the risk of attaining diabetic retinopathy. ${ }^{2}$

Majority of DR patients (81\%) in this study had good vision and only $19 \%$ of the respondents had visual acuity of $6 / 12$ or worse in the better eye. Hence many of these diabetic patients may delay seeking early treatment for DR. This result is almost similar with previous study at a primary clinic in Muar. ${ }^{17}$

The development of DR greatly depends on the duration of DM and the control of glucose level, which is measured by the level of HbA1c with odds ratio (OR) ranging from 1.07 to $8.62 .{ }^{16,18-21} \mathrm{In}$ addition to uncontrolled glucose level other risk factors also played their role in the development of DR. This include the age of the patient, smoking status, the existence of other co-morbidities such as hypertension and dyslipidemia, body mass index, central obesity and renal function. ${ }^{16,18-21}$

In this study, we found that uncontrolled diabetes as shown by high mean HbA1c (OR 1.12) or presence of chronic kidney disease (CKD) (OR 3.46) have high risks of developing DR. Interestingly, the study also found that diabetic patient with dyslipidemia has $39 \%$ lower risk to develop DR which goes against previous studies. ${ }^{18-21}$ The use of statins in most of diabetic patients with dyslipidemia was shown to prevent the progression of DR. ${ }^{22-23}$

In conclusion, the overall prevalence of DR in this study was $33.5 \%$ and most of these patients has had diabetes for less than 5 years and still presented with good vision. Hence, many of these diabetics may not be inclined to seek early eye check-up and treatment for DR. Diabetic patients with CKD had the highest risk ( 3.4 folds) of developing $D R$, which is followed by high HbA1c status (1.1 folds). Dyslipidemia on treatment was shown to have a protective effect from developing DR among diabetic patients in this study. With appropriate training, primary health care providers can contribute and support diabetic eye screening program.

\section{CONFLICTS OF INTEREST}

The authors declare that they have no conflict of interest.

\section{ACKNOWLEDGEMENT}

This study was supported by International Islamic University Malaysia (IIUM) Endowment Fund Type B. Special thanks and appreciation to Ministry of Health Malaysia especially to District Health Office, Kuantan and all government primary clinics in Kuantan who were involved in this study.

\section{REFERENCES}

1. International Diabetes Federation and World Health Organization. The Western Pacific Declaration on Diabetes, Kuala Lumpur, June 2000. Manila: WHO, 2000.

2. World Health Organization. Prevention of Blindness from Diabetes Mellitus, Report of WHO Consultation. Geneva: WHO, 2005.

3. Letchuman GR, Nazaimoon WMW, Mohamad WBW, et al. Prevalence of Diabetes in the 
Malaysian National Health Morbidity Survey III 2006. Med J Malaysia 2010; 65:173-9.

4. The Fourth National Health Morbidity Survey (NHMS IV). Ministry of Heath Malaysia, 2011.

5. Ferris FL III. How effective are treatments for diabetic retinopathy? JAMA. 1993;269(10):12901291.

6. Gill JM, Cole DM, Lebowitz HM, et al. Accuracy of screening for diabetic retinopathy by family physicians. Ann Fam Med 2004; 2:218-220.

7. Early Treatment Diabetic Retinopathy Study (ETDRSR): Grading diabetic retinopathy from stereoscopic colour fundus photographs: an extension of the modified Airlie House classification. Ophthalmology 1991; 98(suppl. 5):786-806.

8. Harris MI. Diabetes in America: epidemiology and scope of the problem. Diabetes Care 1998; 21(suppl. 3):C11-14.

9. Hansen $A B$, Hartvig NV, Jensen MS, et al. Diabetic retinopathy screening using digital non -mydriatic fundus photography and automated image analysis. Acta Ophthalmologica Scand 2004; 82:666-672.

10. UK Prospective Diabetes Study Group. Intensive blood glucose control with sulphonylureas or insulin compared with conventional treatment and risk of complications in patients with Type II diabetes. Lancet 1998; 352:839-855.

11. Kuo HK, Hsieh HH, Liu RT. Screening for diabetic retinopathy by one-field, nonmydriatic, 45 degrees digital photography is inadequate. Ophthalmologica 2005; 219:292296.

12. Mafauzy M. Diabetes control and complications in private primary health care in Malaysia. Medical Journal Malaysia 2005; 60: 212-217.

13. Ministry of Health $(\mathrm{MOH})$ Malaysia. Clinical Practice Guideline Management of Type 2 Diabetes Mellitus ( $5^{\text {th }}$ Edition). $\mathrm{MOH}$ Malaysia, 2015.

14. Wilkinson CP, Ferris FL III, Klein RE, et al. Proposed international clinical diabetic retinopathy and diabetic macular edema disease severity scales. Ophthalmology 2003; 110:1679-80.

15. Goh PP, National Eye Database Study Group. Status of diabetic retinopathy among diabetics registered to the Diabetic Eye Registry, National Eye Database, 2007. Med J Malaysia 2008; 63 (suppl.):C24-8.
16. Wong TY, Cheung N, Tay WT, et al. Prevalence and risk factors for diabetic retinopathy: the Singapore Malay Eye Study. Ophthalmology 2008 Nov; 115:1869-75.

17. Keah SH,Chng KS. Prevalence of diabetic retinopathy in a primary care setting using digital retinal imaging technology. Malaysian Family Physician J 2006; 1:19-22.

18. Rani PK, Raman R, Chandrakantan A, et al. Risk factors for diabetic retinopathy in self-reported rural population with diabetes. Postgrad Med J 2009; 55:92-6.

19. Lim MC, Lee SY, Cheng BC, et al. Diabetic retinopathy in diabetics referred to a tertiary centre from a nationwide screening programme. Ann Acad Med Singapore 2008; 37:753-9.

20. Krishnaiah S, Das T, Nirmalan PK, et al. Risk factors for diabetic retinopathy: Findings from The Andhra Pradesh Eye Disease Study. Clinical Ophthalmology 2007; 1:475-82.

21. Paul Mitchell, Suriya F, Tien $Y$ W, et al. The Australian Diabetes society for the Department of Health and Ageing. Guidelines for the Management of Diabetes Retinopathy. Canberra: NHMRC; 2008; 48-57

22. Gupta A, Gupta V, Thapar S, Bhansali A. Lipidlowering drug atorvastatin as an adjunct in the management of diabetic macular edema. Am J Ophthalmology 2004;137 (4) 675- 682

23. Sen K, Misra A, Kumar A, Pandey RM. Simvastatin retards progression of retinopathy in diabetic patients with hypercholesterolemia. Diabetes Research and Clinical Practice 2002;56 (1) 1- 11 